\title{
Specific reversal of tumor-suppressor gene promoter hypermethylation with bovine oocyte extract
}

\author{
ZHENFEI WANG, HAIXIA GAO, HUIMIN WANG, XIAOLU REN, LURI BAO, \\ RULA SA, JIE WANG, HAIDONG BAI and HAIQUAN YU
}

The Key Laboratory of Mammal Reproductive Biology and Biotechnology, Ministry of Education, Inner Mongolia University, Huhhot 010021, P.R. China

Received February 6, 2013; Accepted April 4, 2013

DOI: $10.3892 /$ or.2013.2449

\begin{abstract}
Epigenetic silencing of tumor-suppressor genes by promoter hypermethylation contributes considerably to the initiation and progression of cancer. Nucleoside analogs, the most widely used DNA methylation inhibitors, have the drawbacks of inducing repetitive sequence hypomethylation. Here, we aimed to specifically reverse tumor-suppressor gene (TSG) promoter hypermethylation with bovine oocyte extract. H460 human lung cancer cells were reversibly permeabilized and incubated with bovine oocyte extract for $3.5 \mathrm{~h}$. The extract treatment led to significant demethylation of the hypermethylated promoters of the TSGs RUNX3,CDH1, RASSF1A and WIFl; however, the methylation levels of repetitive sequences were not affected. The promoter demethylation induced by bovine oocyte extract substantially upregulated the expression of RUNX3, CDH1, RASSF1A and WIF1, and significantly inhibited the anchorage-independent proliferation, migration and invasion of H460 cells. This study demonstrates that bovine oocyte extract can reverse the malignant phenotype by serving as an efficient and safe DNA demethylator. The active demethylation activity of bovine oocyte extract is valuable for dissecting the epigenetic alterations in cancer cells and developing novel safe anticancer drugs based on epigenetic mechanisms.
\end{abstract}

\section{Introduction}

Hypermethylation of the $\mathrm{CpG}$ islands in tumor-suppressor gene (TSG) promoters is one hallmark of the cancer epigenome. This aberrant hypermethylation silences many important TSGs that regulate cell proliferation, differentiation, death, invasion and other cellular processes, promoting cancer initia-

Correspondence to: Dr Haiquan Yu, The Key Laboratory of Mammal Reproductive Biology and Biotechnology, Ministry of Education, Inner Mongolia University, 235 West College Road, Huhhot 010021, P.R. China

E-mail: haiquan_yu@yahoo.com

Key words: bovine oocyte extract, demethylation, tumor-suppressor gene, promoter tion, progression and metastasis (1). Therefore, reactivation of TSG expression by reversing promoter $\mathrm{CpG}$ island hypermethylation has attracted considerable attention in cancer research.

At present, nucleoside analogs such as 5-azacytidine and 5-aza-2'-deoxycytidine are widely used to reduce DNA methylation. These analogs become incorporated into the DNA of rapidly growing cells during replication, where the modified cytosine rings form covalent complexes with DNA methyltransferases, which traps and leads to depletion of these enzymes, thus inhibiting DNA methylation (1). However, targeting DNA methyltransferases leads to the problem of loss of specificity. Apart from demethylating the CpG islands in TSG promoters, nucleoside analogs also induce repetitive sequence hypomethylation, an event that promotes the malignant phenotype (1-3). For example, treatment of rat chondrosarcoma cells with 5-aza2-deoxycytidine led to hypomethylation of LINEs and satellite DNA sequences, accompanied by enhanced tumorigenesis and invasiveness of the cells (2). Treatment of human acute lymphoblastic leukemia cells with 5-aza-2-deoxycytidine induced hypomethylation of LINE-1 repeat elements and elicited their retrotransposition, which subsequently activated the proto-oncogene $c$-MET (3). Therefore, specific demethylation of the hypermethylated $\mathrm{CpG}$ islands in TSG promoters would provide a promising safe method for cancer therapy based on epigenetic mechanisms.

Active DNA demethylation is a direct enzymatic process that converts 5-methylcytosine to cytosine or 5-hydroxymethylcytosine (4). A number of active demethylation mechanisms exist in animal oocytes. In mouse, pig, bovine and human zygotes, oocyte components catalyze rapid demethylation of the paternal genome within a few hours of fertilization (5). When a somatic nucleus is transplanted into an enucleated oocyte, the ooplasm also drives demethylation of the somatic nuclear DNA before replication begins (6). High levels of this demethylation activity can be retained in oocyte extract and exhibit genomic element specificity. Bian et al (7) induced specific demethylation of the OCT4 promoter without affecting the methylation levels of major satellite repeats and imprinted gene H19, by incubating reversibly permeabilized mouse fibroblasts in axolotl oocyte extract. Treatment of reversibly permeabilized fibroblasts with porcine oocyte extract by Miyamoto et al (8) led to demethylation of the NANOG promoter, but did not change the methylation status of centromeric satellite regions. 
Table I. Bisulfite sequencing primers.

\begin{tabular}{|c|c|}
\hline Gene name & $\begin{array}{l}\text { Forward primer }(\mathrm{F}) \\
\text { Reverse primer }(\mathrm{R})\end{array}$ \\
\hline$R U N X 3$ & $\begin{array}{l}\text { F: TAGTTTTGTAGAGGGTTTTTTAGTG } \\
\text { R: AATTAAAACCAACATTAACCTAAAC }\end{array}$ \\
\hline $\mathrm{CDH} 1$ & $\begin{array}{l}\text { F: AATAAAAGAATTTAGTTAAGTGT } \\
\text { R: GTTGTTGTTGTTGTAGGTATT }\end{array}$ \\
\hline$R A S S F 1 A$ & $\begin{array}{l}\text { F: TTATTTAGTGGGTAGGTTAAGTGTGTT } \\
\text { R:AAACCTAAATACAAAAACTATAAAACCC }\end{array}$ \\
\hline WIF1 & $\begin{array}{l}\text { F: GAGTGATGTCCCAGGGGTCTCT } \\
\text { R: CCTAAATACCAAAAAACCTAC }\end{array}$ \\
\hline $\begin{array}{l}\text { Alpha } \\
\text { satellites }\end{array}$ & $\begin{array}{l}\text { F: TAATTAATTAAACCCCTTT } \\
\text { R: TTTTTATGTTTAAGATTGG }\end{array}$ \\
\hline $\begin{array}{l}\text { Retroviral LTR of } \\
\text { minisatellite MS32 }\end{array}$ & $\begin{array}{l}\text { F: CCACTCAAACATAAATTTAA } \\
\text { R: GTTTAGATTGTGTAGTTTAA }\end{array}$ \\
\hline
\end{tabular}

LTR, long terminal repeat.

However, no study has investigated whether the active demethylation activity of oocyte extract can be used to specifically reverse the $\mathrm{CpG}$ island hypermethylation in the promoters of TSGs in cancer cells.

In this study, for the first time we incubated reversibly permeabilized human lung cancer cells with bovine oocyte extract. The treatment led to significant demethylation of the hypermethylated $\mathrm{CpG}$ islands in TSG promoters, while the methylation levels of repetitive sequences were not affected. The demethylation upregulated the transcription of the repressed TSGs and inhibited the malignant phenotype of the cancer cells.

\section{Materials and methods}

Bovine oocyte collection and maturation. Ovaries were collected from freshly slaughtered healthy cows, and transported to the laboratory within $3 \mathrm{~h}$. Cumulus oocyte complexes (COCs) were aspired from follicles $2-8 \mathrm{~mm}$ in diameter. $\mathrm{COCs}$ with compact cumulus cells were collected and incubated in TCM-199 supplemented with $10 \%$ fetal bovine serum (FBS), $0.38 \mathrm{mmol} / 1$ sodium pyruvate, $10 \mu \mathrm{g} / \mathrm{ml}$ follicle-stimulating hormone, $5 \mu \mathrm{g} / \mathrm{ml}$ luteinizing hormone and $1 \mu \mathrm{g} / \mathrm{ml}$ $17-\beta$-estradiol for $22 \mathrm{~h}$ at $38.5^{\circ} \mathrm{C}$ in $5 \% \mathrm{CO}_{2}$ in humidified air.

Bovine oocyte extract preparation. Bovine oocyte extract was prepared as described previously with minor changes (8). Briefly, the matured COCs were digested with $0.1 \%$ hyaluronidase to remove cumulus cells. Oocytes with a first polar body and even cytoplasm were digested with $0.5 \%$ pronase to remove the zona pellucida. The zona-free oocytes were transferred into $1.5-\mathrm{ml}$ tubes and washed three times with extraction buffer $\left(5 \mathrm{mM} \mathrm{MgCl}_{2}, 60 \mathrm{mM} \mathrm{NaCl}, 2 \mathrm{mM} \beta\right.$-mercaptoethanol, protease inhibitor cocktail, $5 \mathrm{mM}$ EGTA and $50 \mathrm{mM}$ HEPES, $\mathrm{pH}$ 7.4) containing an energy regenerating system (2 mM ATP, $20 \mathrm{mM}$ phosphocreatine, $20 \mathrm{U} / \mathrm{ml}$ creatine kinase and $2 \mathrm{mM}$
Table II. Real-time PCR primers.

\begin{tabular}{ll}
\hline Gene name & \multicolumn{1}{c}{$\begin{array}{c}\text { Forward primer (F) } \\
\text { Reverse primer (R) }\end{array}$} \\
\hline GAPDH & F: TGTCCCCACTGCCAACGTGTCA \\
& R: GCGTCAAAGGTGGAGGAGTGGGT \\
FUNX3 & F: CAGCACCACAAGCCACTTCA \\
& R: GGTCGGAGAATGGGTTCAGTT \\
FDH1 & F: CGGGAATGCAGTTGAGGATC \\
& R: AGGATGGTGTAAGCGATGGC \\
& F: ACCTCTGTGGCGACTTCATCT \\
RIF1 AGGTGAACTTGCAATGCG & F: TGAATTTTACCTGGCAAGCTG \\
& R: GGACATTGACGGTTGGATCT \\
\hline
\end{tabular}

GTP). The washed oocytes were resuspended (100 oocytes/ $\mu \mathrm{l})$ in extraction buffer containing the energy-regenerating system, and disrupted by centrifugation twice at 20,800 $\mathrm{x}$ g for $30 \mathrm{~min}$ at $4^{\circ} \mathrm{C}$. The lysate was mixed by pipetting, and subsequently centrifuged at $5,000 \times \mathrm{g}$ for $10 \mathrm{~min}$ at $4^{\circ} \mathrm{C}$. The supernatant was used as the oocyte extract.

Oocyte extract treatment. The human non-small cell lung cancer (NSCLC) cell line NCI-H460 was cultured in RPMI-1640 medium supplemented with $10 \% \mathrm{FBS}$ at $37^{\circ} \mathrm{C}$ with $5 \% \mathrm{CO}_{2}$. For permeabilization, $2 \times 10^{6} \mathrm{H} 460$ cells were collected and suspended in $20 \mu \mathrm{g} / \mathrm{ml}$ digitonin solution for $2 \mathrm{~min}$. Permeabilization was assessed by monitoring the uptake of $70-\mathrm{kDa}$ FITC-dextran $(40 \mu \mathrm{g} / \mathrm{ml})$ in a separate sample after resealing the plasma membranes (9). The permeabilized cells were suspended in bovine oocyte extract $(5,000$ cells $/ 10 \mu 1$ extract; extract-treated cells) or an equal volume of extraction buffer (buffer-treated cells) at $38.5^{\circ} \mathrm{C}$ for $3.5 \mathrm{~h}$ with occasional tapping. For membrane resealing, the cell suspension was diluted with $1 \mathrm{ml}$ RPMI-1640 containing $2 \mathrm{mM} \mathrm{CaCl}_{2}$, and incubated for $2 \mathrm{~h}$ at $37^{\circ} \mathrm{C}$. After pelleting by centrifugation at $400 \mathrm{x} \mathrm{g}$ for $5 \mathrm{~min}$, the cells were subjected to normal culture or used directly for assays.

Bisulfite sequencing. DNA was isolated from cells using the Wizard ${ }^{\circledR}$ SV genomic DNA purification system (Promega Corporation, Madison, WI, USA). Bisulfite conversion was performed using the EZ DNA methylation kit (Zymo Research, Irvine, CA, USA ) according to the vendor's recommendations. Bisulfite converted DNA was amplified with the primers listed in Table I. The PCR products were then cloned into the vector pEASY-T1 (Transgene, China), with at least 10 clones from each sample subjected to sequencing.

Quantitative real-time PCR. Total RNA was isolated using RNAiso reagent, and reverse transcribed using the PrimeScript RT reagent kit (both from Takara Bio, Inc., Shiga, Japan). Real-time PCR was performed using the primers described in Table II and SYBR Premix Ex Taq (Takara Bio, Inc.) in triplicate on a 7300 Real-Time PCR system (Applied Biosystems, Foster City, CA, USA). The relative expression levels of each 
gene were calculated using the $\triangle \triangle \mathrm{Ct}$ method using GAPDH as an endogenous control.

Soft agar assay. A $0.6 \%$ (wt/vol) solution of low melting point agar was prepared in normal medium, placed into 6-well culture plates, and allowed to solidify. A layer of $0.3 \%$ low melting point agar containing $1 \times 10^{4}$ cells was gently placed on top. The cells were incubated in a humidified atmosphere $\left(5 \% \mathrm{CO}_{2}\right)$ at $37^{\circ} \mathrm{C}$, and the number of colonies larger than $100 \mu \mathrm{m}$ was counted after 3 weeks.

Cell migration and invasion assay. Migration and invasion assays were performed using 24-well Transwell chambers (polycarbonate membrane, $8-\mu \mathrm{m}$ pore size; Costar). For the migration assay, $4 \times 10^{4}$ cells suspended in $200 \mu 1$ serum-free RPMI-1640 were placed into each upper chamber, and $600 \mu 1$ of RPMI-1640 containing 20\% FCS was placed into each lower chamber as a chemoattractant. The plates were incubated for $24 \mathrm{~h}$ at $37^{\circ} \mathrm{C}$, then the medium was removed from the Transwell chambers, and the cells on the upper surface of the Transwell membrane were wiped off. Cells that had migrated to the lower surface of the Transwell membrane were fixed, stained with hematoxylin, and the number of cells in five randomly selected fields at x200 magnification were counted. Three independent experiments were performed.

For the invasion assay, the upper surfaces of the Transwell membranes were pre-coated with Matrigel (diluted 1:7; BD Biosciences, Franklin Lakes, NJ, USA) which was allowed to gel at $37^{\circ} \mathrm{C}$ for $4 \mathrm{~h}$, then the cells were added to the Transwell membranes and the assay was conducted using the same method as that used for the migration assay.

Statistical analysis. Bisulfite sequencing data were analyzed using the $\chi^{2}$ test; real-time PCR data were analyzed using one-way ANOVA; soft agar assay, cell migration assay and cell invasion assay data were analyzed using the unpaired Student's t-test. Significance was accepted at $\mathrm{p}<0.05$.

\section{Results}

Permeabilization assessment. In order to introduce the demethylation factors from bovine oocyte extract into H460 cells, we first permeabilized the membranes of the H460 cells using digitonin, an efficient and mild permeabilization agent. Over $80 \%$ of the permeabilized cells showed uptake of 70-kDa FITCdextran (Fig. 1), indicating that the large molecules in bovine oocyte extract could readily enter the permeabilized H460 cells.

Bovine oocyte extract reverses hypermethylation of TSG promoter CpG islands. The TSGs RUNX3, CDH1, RASSF1A and WIFl are frequently silenced in lung cancer cells due to hypermethylation of the $\mathrm{CpG}$ islands in their promoters. We analyzed the effects of bovine oocyte extract treatment on the methylation of the promoter CpG islands of these four TSGs. As shown in Fig. 2, the promoter CpG islands of the four TSGs were hypermethylated in the untreated $\mathrm{H} 460$ cells. The methylation levels of the $\mathrm{CpG}$ islands of the four TSGs were similar in the buffer-treated cells and untreated cells (Fig. 2). In the extract-treated cells, incubation in the bovine oocyte extract induced significant demethylation of the $\mathrm{CpG}$ islands in the

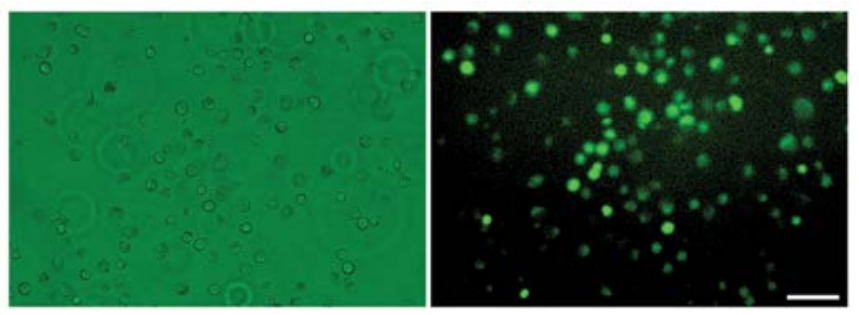

Figure 1. FITC-dextran staining of the permeabilized H460 cells. Left: phase contrast image, right: fluorescent image. Scale bar, $50 \mu \mathrm{m}$.

Table III. Demethylated CpG sites residing in the transcription factor binding regions.

\begin{tabular}{lcccc}
\hline & RUNX3 & CDH1 & RASSF1A & WIF1 \\
\hline Sp1 & 7,14 & 17 & 11,17 & 12 \\
CP2 & 14 & - & - & - \\
GATA-2 & - & - & 2 & 32 \\
SRY & - & 12 & - & - \\
Tst-1 & - & 4 & - & - \\
p300 & - & - & - & 30 \\
\hline
\end{tabular}

Transcription factor binding regions were determined by TFSEARCH (http://www.cbrc.jp/research/db/TFSEARCH.html).

four TSGs (Fig. 2). The methylation levels were decreased by $30.94 \%$ for $R U N X 3$, by $38.15 \%$ for $C D H 1$, by $20.45 \%$ for RASSF $1 A$ and by $20.06 \%$ for WIF 1 , compared to the buffertreated cells.

The extract-induced demethylation at the $\mathrm{CpG}$ islands was not randomly distributed among the $\mathrm{CpG}$ sites. The demethylation focused on $\mathrm{CpG}$ sites 7,13 and 14 for $R U N X 3$; sites 4, 7, 10, 11, 13, 17 and 25 for $C D H 1$; sites 2, 11, 17 and 18 for RASSF1A; and sites 10-12 and 30-35 for WIFl. Many of these CpG sites reside in transcription factor binding regions, particularly the binding regions for the transcription factor Sp1 (Table III).

These results indicated that the bovine oocyte extract induced efficient and site-specific demethylation at the $\mathrm{CpG}$ islands in the TSG promoters.

Bovine oocyte extract does not demethylate repetitive sequences. We next examined whether the bovine oocyte extract treatment led to demethylation of repetitive sequences. The alpha satellite sequence and retroviral long terminal repeat (LTR) sequence of minisatellite MS32 were selected for analysis. Bisulfite sequencing demonstrated that the methylation levels of these sequences were similar in untreated, buffer-treated and extract-treated cells (Fig. 3), suggesting that the bovine oocyte extract did not induce hypomethylation of repetitive sequences.

Bovine oocyte extract upregulates transcription of the four TSGs. Since DNA hypermethylation of promoter CpG islands silences gene transcription, we investigated whether the bovine oocyte extract-induced demethylation activates transcription of the four tested TSGs. After returning to culture for $6 \mathrm{~h}$, the extract-treated cells displayed a marked increase in 


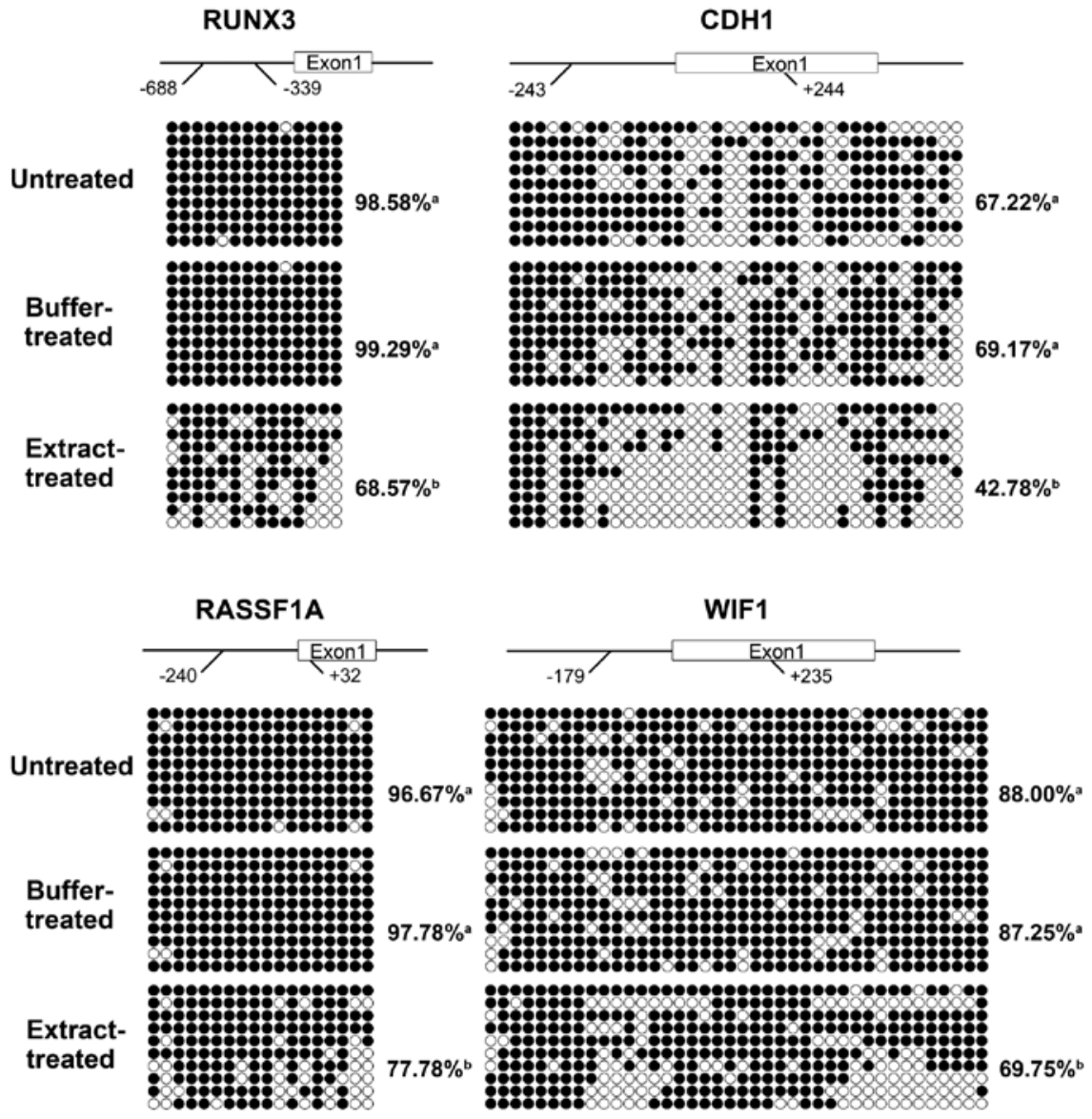

Figure 2. Treatment with bovine oocyte extract leads to demethylation of the promoter CpG islands of the four tested TSGs in H460 cells. Schematics indicate the positions of the promoter $\mathrm{CpG}$ islands analyzed. The open circles $(\mathrm{O})$ represent unmethylated $\mathrm{CpG}$ sites, and closed circles $(\bullet)$ represent methylated $\mathrm{CpG}$ sites. The methylation level of each region is presented as the number of methylated $\mathrm{CpG}$ sites as a percentage of the total number of unmethylated and methylated $\mathrm{CpG}$ sites. a vs. a: $\mathrm{p}>0.05$; a vs. b: $\mathrm{p}<0.05$.

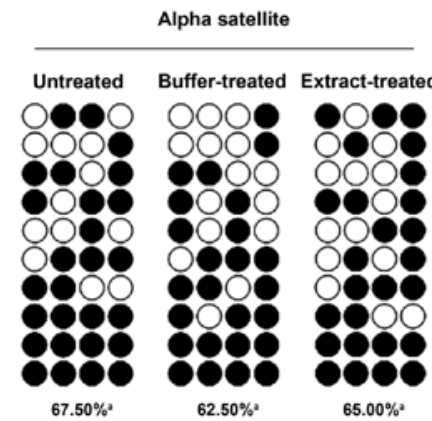

$65.00 \%^{2}$

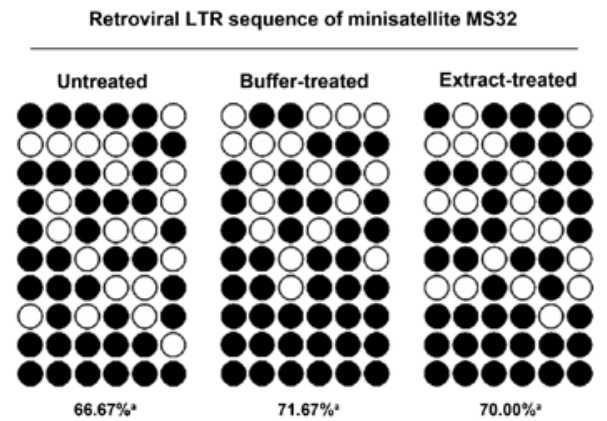

$66.67 \%$
$71.67 \%$

$70.00 \%$

Figure 3. Treatment with bovine oocyte extract does not affect the DNA methylation levels of the alpha satellite and retroviral long terminal repeat (LTR) sequence of minisatellite MS32 in H460 cells. The open circles (O) represent unmethylated CpG sites, and closed circles (•) represent methylated CpG sites. The methylation level of each region is presented as the number of methylated CpG sites as a percentage of the total number of unmethylated and methylated CpG sites. a vs. a: $\mathrm{p}>0.05$.

transcription of the four TSGs, compared to the untreated and buffer-treated cells (Fig. 4). The increase was more obvious for $R U N X 3$ and $C D H 1$, consistent with the greater degree of demethylation observed in their promoter $\mathrm{CpG}$ islands in response to the bovine oocyte extract. After return to culture for $24 \mathrm{~h}$, transcription of the four TSGs was further upregulated in extract-treated cells (Fig. 4). The expression levels of the four TSGs were not significantly different in the buffer-treated and untreated cells, indicating that the permeabilization process did not upregulated the expression of the four TSGs.
Bovine oocyte extract inhibits the malignant phenotype of H460 cells. The TSGs RUNX3, CDH1, RASSF1A and WIF1 play important roles in the regulation of cell proliferation, migration and invasion. Thus, we next investigated the effect of bovine oocyte extract treatment on the malignant phenotype of $\mathrm{H} 460$ cells. Buffer-treated cells were used as a control. In the soft agar assay, the extract-treated cells formed significantly fewer and smaller colonies than in the buffertreated cells (Fig. 5). In the migration assay, the number of extract-treated cells that migrated through the Transwell 

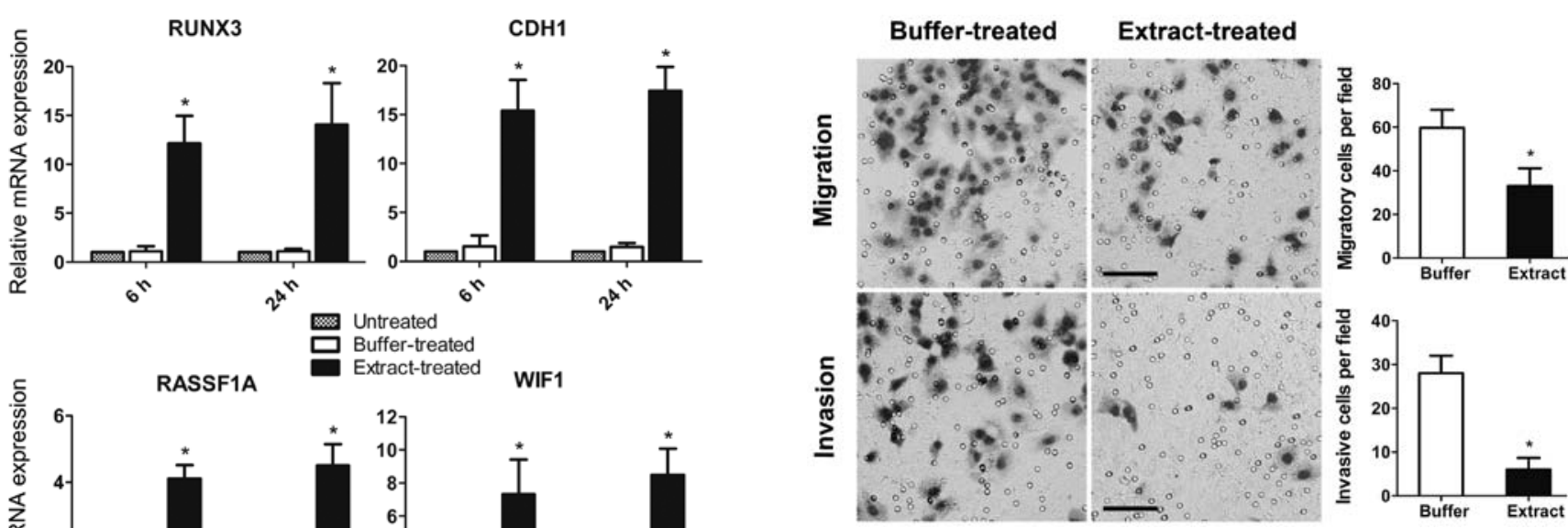

Figure 6. Treatment with bovine oocyte extract inhibits migration and Matrigel invasion by $\mathrm{H} 460$ cells. Error bars represent the SD; ${ }^{*} \mathrm{p}<0.05$ vs. buffer-treated cells. Scale bars, $50 \mu \mathrm{m}$.

Figure 4. Treatment with bovine oocyte extract upregulates the transcription of the four tested TSGs in H460 cells. Error bars represent the SD; ${ }^{p}<<0.05$ vs. untreated and buffer-treated cells.
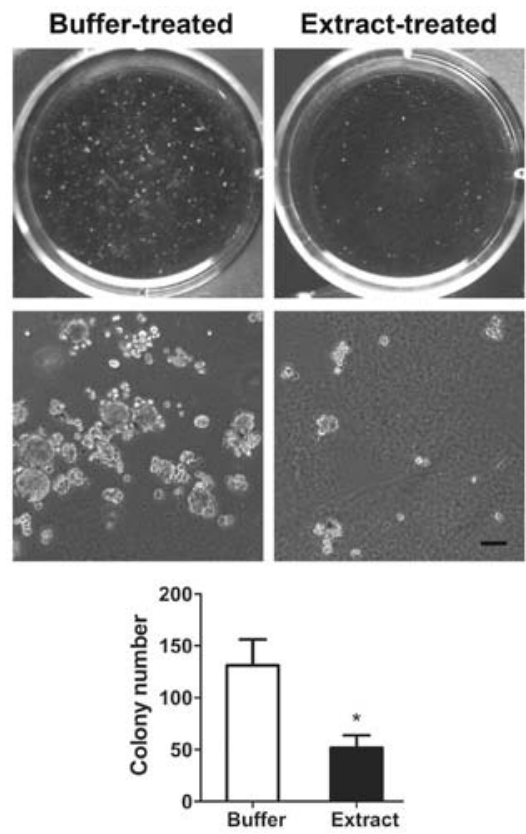

Figure 5. Treatment with bovine oocyte extract inhibits soft agar colony formation by $\mathrm{H} 460$ cells. Error bars represent the $\mathrm{SD} ;{ }^{*} \mathrm{p}<0.05$ vs. buffer-treated cells. Scale bar, $100 \mu \mathrm{m}$.

membrane was $40.72 \%$ lower than the number of migrating buffer-treated cells (Fig. 6). In the invasion assay, the number of extract-treated cells that passed through the Matrigel barrier was $78.05 \%$ lower than the number of invasive buffer-treated cells (Fig. 6). Thus, bovine oocyte extract treatment strongly reduced the anchorage-independent proliferation, migration and invasive capacity of $\mathrm{H} 460$ cells.

\section{Discussion}

A number of innate active DNA demethylation mechanisms exist in mammals to drive rapid DNA demethylation in specific sequences at various developmental stages. Exposure of cancer

cells to these active demethylation mechanisms may help to understand the epigenetic mechanisms leading to repression of TSG expression, and help explore new epigenetic-based anticancer approaches. In this study, we investigated the specific reversal of $\mathrm{CpG}$ island hypermethylation in TSG promoters using the active DNA demethylation activity of bovine oocytes.

The extract-treated cells displayed significant demethylation of the TSG promoter CpG islands after only a 3.5-h incubation with the bovine oocyte extract. As this incubation time was short and the cells were suspended in a serum-free environment during incubation, the extract-induced demethylation was an active process independent of DNA replication. Of the molecules which have been identified to possess active demethylation activity, at least methyl-CpG-binding domain protein 4 (MBD4) (10), activation-induced cytidine deaminase (AID) (11), teneleven translocation 3 (TET3) (12), elongator complex protein 3 (ELP3) (4), DNA methyltransferase 3A (DNMT3A) (10) and DNA methyltransferase 3B (DNMT3B) (10) are expressed in oocytes. These proteins, except for DNMT3A and DNMT3B, have a molecular weight lower than $70 \mathrm{kDa}$, particularly AID, whose molecular weight is only $24 \mathrm{kDa}$. Therefore, these proteins readily enter permeabilized cells to catalyze active demethylation, converting 5-methylcytosine to cytosine or 5-hydroxymethylcytosine.

The bovine oocyte extract upregulated expression of the repressed tumor-suppressor genes by demethylating several specific $\mathrm{CpG}$ sites rather than all of the $\mathrm{CpG}$ sites within each $\mathrm{CpG}$ island. This avoids aggravating the genome hypomethylation in cancer cells, and favors revealing key regulatory sequences in the $\mathrm{CpG}$ islands. Many of the demethylated $\mathrm{CpG}$ sites reside in transcription factor binding regions, suggesting that demethylation of the $\mathrm{CpG}$ sites within transcription factor binding regions plays an important role in transcriptional activation. It may be that the methylation modification of these $\mathrm{CpG}$ sites hinders transcription factors from binding to the promoters or provides proper binding sites for chromatin condensation factors.

Studies have demonstrated that apart from reversing the hypermethylation of TSG promoters, nucleoside analogs also induce hypomethylation of repetitive sequences such as 
satellite DNA sequences $(2,13)$. Hypomethylation of repetitive sequences increases genome instability by promoting chromatin rearrangement and activating transposable elements, thereby inducing or aggravating the malignant phenotype. Notably, bovine oocyte extract treatment did not affect the DNA methylation levels of repetitive sequences; rather it specifically demethylated the hypermethylated TSG promoters. This suggests that bovine oocyte extract treatment may provide a safe demethylation approach. Paternally methylated imprinted genes, intracisternal A particle retrotransposons, and heterochromatin in and around the centromeres remain unaffected during the demethylation of the paternal genome by ooplasm after fertilization. Therefore, the process of ooplasm-driven demethylation is intrinsically genome element-selective, and this genome element-selective attribute was well preserved during the treatment of cancer cells with bovine oocyte extract.

Bisulfite sequencing showed that the promoter $\mathrm{CpG}$ islands of RUNX3, CDH1, RASSF1A and WIF1 were all hypermethylated in untreated $\mathrm{H} 460$ cells. Hypermethylation of promoter $\mathrm{CpG}$ islands induces closed chromatin conformations, which prevent transcription factors from binding to the gene promoters, resulting in transcriptional repression. Previous studies have demonstrated that the expression of the four TSGs is silenced in H460 cells (14-17). However, the extract-treated cells displayed significant transcriptional upregulation of the four TSGs after being returned to culture for $6 \mathrm{~h}$. This observation suggests that bovine oocyte extract treatment can rapidly alter the aberrant chromatin structure and quickly reestablish a relatively open chromatin conformation around these four TSG promoters in H460 cells. In contrast, nucleoside analoginduced TSG activation usually requires a treatment time of 3 days or longer, with treatment for shorter times such as $24 \mathrm{~h}$ often generating no effect (15).

Anchorage-independent colony formation in soft agar is a highly clinically relevant model for evaluating NSCLC cell proliferation (18). Compared to the buffer-treated cells, the extract-treated cells only formed a few small clones after a 3-week culture in soft agar. Thus, the upregulation of TSG expression by bovine oocyte extract treatment led to long-term inhibition of cancer cell proliferation.

The vaccinia vaccine has been reliably administered to human beings for centuries. Bovine insulin and thymic peptides have also been widely used in the clinical therapy of human diseases, and these treatments are safe and have a high efficacy. In this study, we demonstrated that bovine oocyte extract can specifically reverse promoter $\mathrm{CpG}$ island hypermethylation of TSGs without inducing hypomethylation of repetitive sequences.

The promoter demethylation upregulates the expression of epigenetically repressed TSGs and inhibits the malignant phenotype of H460 cells. Thus, bovine oocyte extract may provide a useful tool for investigating the epigenetic alterations in cancer cells, and may represent a promising source of drugs for epigenetic-based therapy of human diseases.

\section{Acknowledgements}

This study was supported by a grant from the Major Program of the Inner Mongolia Natural Science Foundation (No. 2012ZD04), and a grant from NSFC (No. 30860185).

\section{References}

1. Huang YW, Kuo CT, Stoner K, Huang TH and Wang LS: An overview of epigenetics and chemoprevention. FEBS Lett 585: 2129-2136, 2011.

2. Hamm CA, Xie H, Costa FF, Vanin EF, Seftor EA, Sredni ST, Bischof J, Wang D, Bonaldo MF, Hendrix MJ and Soares MB: Global demethylation of rat chondrosarcoma cells after treatment with 5-aza-2'-deoxycytidine results in increased tumorigenicity. PLoS One 4: e8340, 2009.

3. Roman-Gomez J, Jimenez-Velasco A, Agirre X, Cervantes F, Sanchez J, Garate L, Barrios M, Castillejo JA, Navarro G, Colomer D, Prosper F, Heiniger A and Torres A: Promoter hypomethylation of the LINE-1 retrotransposable elements activates sense/antisense transcription and marks the progression of chronic myeloid leukemia. Oncogene 24: 7213-7223, 2005.

4. Wu SC and Zhang Y: Active DNA demethylation: many roads lead to Rome. Nat Rev Mol Cell Biol 11: 607-620, 2010.

5. Morgan HD, Santos F, Green K, Dean W and Reik W: Epigenetic reprogramming in mammals. Hum Mol Genet 14: R47-R58, 2005.

6. Dean W, Santos F, Stojkovic M, Zakhartchenko V, Walter J, Wolf $E$ and Reik W: Conservation of methylation reprogramming in mammalian development: aberrant reprogramming in cloned embryos. Proc Natl Acad Sci USA 98: 13734-13738, 2001.

7. Bian Y, Alberio R, Allegrucci C, Campbell KH and Johnson AD: Epigenetic marks in somatic chromatin are remodelled to resemble pluripotent nuclei by amphibian oocyte extracts. Epigenetics 4: 194-202, 2009

8. Miyamoto K, Tsukiyama T, Yang Y, Li N, Minami N, Yamada M and Imai $\mathrm{H}$ : Cell-free extracts from mammalian oocytes partially induce nuclear reprogramming in somatic cells. Biol Reprod 80: 935-943, 2009.

9. Ostrup O, Hyttel P, Klaerke DA and Collas P: Remodeling of ribosomal genes in somatic cells by Xenopus egg extract. Biochem Biophys Res Commun 412: 487-493, 2011.

10. Oliveri RS, Kalisz M, Schjerling CK, Andersen CY, Borup R and Byskov AG: Evaluation in mammalian oocytes of gene transcripts linked to epigenetic reprogramming. Reproduction 134: 549-558, 2007.

11. Morgan HD, Dean W, Coker HA, Reik W and PetersenMahrt SK: Activation-induced cytidine deaminase deaminates 5-methylcytosine in DNA and is expressed in pluripotent tissues: implications for epigenetic reprogramming. J Biol Chem 279: 52353-52360, 2004.

12. Iqbal K, Jin SG, Pfeifer GP and Szabó PE: Reprogramming of the paternal genome upon fertilization involves genome-wide oxidation of 5-methylcytosine. Proc Natl Acad Sci USA 108: 3642-3647, 2011.

13. Daskalos A, Nikolaidis G, Xinarianos G, Savvari P, Cassidy A, Zakopoulou R, Kotsinas A, Gorgoulis V, Field JK and Liloglou T: Hypomethylation of retrotransposable elements correlates with genomic instability in non-small cell lung cancer. Int J Cancer 124: 81-87, 2009.

14. Li QL, Kim HR, Kim WJ, Choi JK, Lee YH, Kim HM, Li LS, Kim H, Chang J, Ito Y, Youl Lee K and Bae SC.: Transcriptional silencing of the RUNX3 gene by CpG hypermethylation is associated with lung cancer. Biochem Biophys Res Commun 314: 223-228, 2004

15. Reinhold WC, Reimers MA, Lorenzi P, Ho J, Shankavaram UT, Ziegler MS, Bussey KJ, Nishizuka S, Ikediobi O, Pommier YG and Weinstein JN: Multifactorial regulation of E-cadherin expression: an integrative study. Mol Cancer Ther 9: 1-16, 2010.

16. Endoh H, Yatabe Y, Shimizu S, Tajima K, Kuwano H, Takahashi T and Mitsudomi T: RASSF1A gene inactivation in non-small cell lung cancer and its clinical implication. Int J Cancer 106: 45-51, 2003.

17. Mazieres J, He B, You L, Xu Z, Lee AY, Mikami I, Reguart N, Rosell R, McCormick F and Jablons DM: Wnt inhibitory factor-1 is silenced by promoter hypermethylation in human lung cancer. Cancer Res 64: 4717-4720, 2004.

18. Takezawa K, Okamoto I, Yonesaka K, Hatashita E, Yamada Y, Fukuoka M and Nakagawa K: Sorafenib inhibits non-small cell lung cancer cell growth by targeting B-RAF in KRAS wild-type cells and C-RAF in KRAS mutant cells. Cancer Res 69: 6515-6521, 2009 . 